\title{
The Effects of Feeding Reduced-Lignin Alfalfa on Growing Beef Cattle Performance: a Preliminary Study
}

\author{
Danielle M. Peterson \\ Forage Research Lab Manager, Montana State University \\ PO Box 172900, Bozeman, Montana 59717, United States \\ Tel: 1-406-925-2085 E-mail: daniellemarie516@gmail.com
}

Jan G. P. Bowman

Professor, Animal Science, Montana State University

PO Box 172900, Bozeman, Montana 59717, United States

Tel: 1-406-994-5563 E-mail: jbowman@montana.edu

\author{
Rachel L. Endecott
}

Director of Youth Development and Special Projects, American Simmental Association

1 Genetics Way, Bozeman, Montana 59715, United States

Tel: 1-406-581-9278 E-mail: rendecott@simmgene.com

\author{
Andrea L. Mack \\ Statistician, Idaho National Laboratory \\ 2525 Fremont Avenue, Idaho Falls, Idaho 83402, United States \\ Tel: 1-208-526-1617 E-mail: mack.mathstat@gmail.com
}

\author{
Emily C.G. Meccage (Corresponding author) \\ Assistant Professor, Forage Extension Specialist, Montana State University \\ PO Box 172900, Bozeman, Montana 59717, United States \\ Tel: 1-406-994-5688 E-mail: emily.meccage@ montana.edu
}


Mll Macrothink

Received: March 22, 2018

doi:10.5296/jas.v6i2.12872
Journal of Agricultural Studies

ISSN 2166-0379

2018, Vol. 6, No. 2

Accepted: April 13, 2018

URL: https://doi.org/10.5296/jas.v6i2.12872

\begin{abstract}
Gene suppression techniques down-regulating specific lignin biosynthesis pathway enzymes have permitted the development of an alfalfa variety with an altered lignin content and composition known as HarvXtra. This study was designed to compare the difference in forage nutrient quality between reduced-lignin alfalfa hay (variety HX-4114) and conventional alfalfa hay (variety WL336HQRR), and to evaluate Angus heifer performance when fed treatments of HX-4114 and WL336HQRR. Twenty-four Angus heifers (8 months of age; initial $\mathrm{BW}=270 \pm 21 \mathrm{~kg}$ ) were selected to participate in an 84-day alfalfa hay feeding trial. Their performance was evaluated based on changes in body weight (BW), average daily gain (ADG), dry matter intake (DMI), and gain to feed ratio (G:F). Additionally, in situ dry matter disappearance was tested using four ruminally cannulated Hereford cows. Hay samples were collected and used to determine forage nutrient quality, leaf count, and leaf-to-stem ratio. Significance was set at $P \leq 0.05$. There were no differences $(P \geq 0.05)$ in forage nutrient quality between alfalfa treatments. Means did not differ by treatment for leaf count $(P=0.06)$, but leaf-to-stem ratio was higher $(P=0.04)$ for $\mathrm{HX}-4114$ than WL336HQRR (1.67 vs. 1.17, respectively). There were no treatment or treatment by day interactions for BW, ADG, DMI, G:F, or in situ dry matter disappearance. Additionally, animal performance did not differ for growing Angus heifers consuming HX-4114 and WL336HQRR alfalfa hay. More research is warranted to determine the value of utilizing different genotypes of reduced-lignin alfalfa and their impact on the U.S beef industry.
\end{abstract}

Keywords: Alfalfa, Beef, Cattle, Heifer, HarvXtra, Performance, Reduced-lignin

\title{
1. Introduction
}

Gene suppression techniques used to decrease lignin content in plants focuses on down-regulating specific enzymes involved in lignin biosynthesis. The use of gene suppression technology to down-regulate the enzyme caffeoyl CoA 3-O-methyltransferase has helped foster the development of a more readily-digested variety of alfalfa known as HarvXtra (McCaslin et al., 2014). Compared to related null lines of alfalfa, HarvXtra is expected to exhibit a 150-200 g/kg reduction in lignin content and a $100-150 \mathrm{~g} / \mathrm{kg}$ increase in neutral detergent fiber digestibility (NDFD) and relative forage quality (RFQ; McCaslin et al., 2014). Improvements in fiber digestibility and lignin concentration can have profound impacts on animal performance measurements such as daily gain, intake, and milk production. Casler and Vogel (1999) reported that when multiple forage species were averaged together, a $1 \mathrm{~g} / \mathrm{kg}$ improvement in in vitro dry matter digestibility (IVDMD) improved average daily gain (ADG) in beef cattle by $3.2 \mathrm{~g} / \mathrm{kg}$. Similarly, Oba and Allen (1999) found that a one-unit increase in NDFD in forage fed to lactating dairy cattle increased dry matter (DM) consumption by $0.17 \mathrm{~kg}$ and increased production of $4 \mathrm{~g} / \mathrm{kg}$ fat-corrected milk by $0.25 \mathrm{~kg}$. 
Previous studies indicate that reducing the lignin content in alfalfa increases NDFD and in situ digestibility when compared to related null lines (Guo et al. 2001; Reddy et al. 2005); however, published research describing the effects of feeding reduced-lignin alfalfa hay in ruminant feeding trials is lacking. One progress report created by the U.S Dairy Forage Research Center reported that feeding reduced-lignin alfalfa hay to lambs significantly improved fiber digestion by nearly $20 \mathrm{~g} / \mathrm{kg}$ and increased ADG by $100 \mathrm{~g} / \mathrm{kg}$ when compared to lambs consuming conventional alfalfa varieties (Mertens, 2009).

Although literature describing reduced-lignin alfalfa hay feeding trials are lacking, feeding trials utilizing other types of low lignin forages in the dairy industry indicate that reducing the lignin content improves dry matter intake (DMI), milk production, and ADG. Evidence of improved performance is demonstrated in dairy cows consuming brown midrib mutant forages (BMR) forages, which exhibit lower lignin content that their non-BMR counterparts. In vitro and in situ neutral detergent fiber (NDF) digestion trials using BMR mutant forages found that BMR forages had lower lignin content and higher NDFD than their null counterparts (Rook et al., 1977; Keith et al., 1979; Cherney et al., 1991). These studies also found that dairy cows consuming BMR varieties exhibited increased DMI, improved milk production, and better weight gain than dairy cows consuming non-BMR forages (Rook et al., 1977; Aydin et al., 1999).

The literature suggests that forages with lower lignin content, such as BMR mutant forages and reduced-lignin alfalfa, are valuable resources, and can be used to maximize animal production. On-going variety trials are looking to maximize reductions in lignin, evaluating impacts of environment on genotypes. Currently, because the development of reduced-lignin alfalfa is relatively new, there has been no research evaluating the potential of HarvXtra in beef cattle operations. Although small plot research provides evidence that reduced-lignin alfalfa is more digestible (Grev et al., 2017; Guo et al. 2001; Reddy et al. 2005), reduction in lignin content and improvement in digestibility varies between studies. This variation is caused by differences in gene selection for lignin down-regulation, environment, and harvest management. Therefore, research is necessary to determine differences in nutrient quality between reduced-lignin alfalfa varieties in small- and large-scale study settings, and subsequent animal feeding trials are necessary to validate improvements in nutrient quality associated with these reduced-lignin alfalfa varieties.

The first objective of this study was to evaluate differences in forage quality between HarvXtra alfalfa (HX-4114), a reduced-lignin alfalfa variety, and WL336HQRR, a conventional alfalfa variety. The second objective of this study was to evaluate Angus heifer performance in a feeding trial using HX-4114 and WL336HQRR alfalfa hay. Based on previously published literature describing the nutritive value of a cultivar similar to HX-4114 (Grev et al.,2017), we hypothesized that heifers consuming the HX-4114 alfalfa variety would weigh more on the final day of sampling and have higher ADG, DMI, and G:F compared to heifers consuming the WL336HQRR alfalfa variety. 


\section{Materials and Methods}

All protocols for this study were reviewed and approved by the Montana State University Agricultural Animal Care and Use Committee (AACUC \#2016-AA15).

\subsection{Forage Establishment, Harvest, and Storage}

The production site was located south of Townsend, MT. Two varieties of alfalfa were established on May 19, 2016, each on 8 ha; one variety of reduced-lignin alfalfa (HX-4114) and one variety of conventional alfalfa (WL336HQRR). Prior to planting, soil samples were collected to determine and apply appropriate fertilizer amounts. Alfalfa was drilled using a Great Plains 3S-3000HD double disc drill at a seeding rate of $3.6 \mathrm{~kg}$ pure live seed/ ha at a $1.27 \mathrm{~cm}$ depth, spaced $15 \mathrm{~cm}$ apart, into a firm, weed-free seedbed. The field was irrigated with a center-pivot that was already in place at the research site.

First and second harvests were taken on July 29, 2016 and October 10, 2016, respectively, at approximately $10 \%$ bloom. Both varieties of alfalfa were baled and twine wrapped at approximately $14 \mathrm{~g} / \mathrm{kg}$ moisture into large square bales using a Krone 1290 HDP baler. Bales from the first harvest were not used in the feeding trial, so production and baling information for the first harvest will not be discussed further. The second harvest, which was used for the feeding trial in this research study, produced alfalfa yields of 2,741 and 2,682 kg/ ha, respectively, for the WL336HQRR and HX-4114 varieties. Average bale weight for both varieties was $609 \mathrm{~kg}$ (DM basis) and average bale dimension was $0.9 \times 1.2 \times 2.4 \mathrm{~m}$ for each bale. Bales in this study were allowed to reach a stable moisture and temperature prior to being stacked on a well-drained site. Bales were stored uncovered at this site for one month, until they were transported to the Bozeman Agricultural Research and Teaching (BART) Farm located west of the Montana State University campus in Bozeman, Montana. Bales were unloaded and stored under a covered hay shed that consisted of one wall on the west side to protect bales from wind and precipitation.

\subsection{Feeding Trial}

Twenty-four Angus heifers (approximately 8 months of age; initial BW $=270 \pm 21 \mathrm{~kg}$ ) were utilized in a completely randomized design in an 84-day trial beginning on November 14, 2016 and ending on February 7, 2017. Heifers were stratified by BW to one of two alfalfa varieties ( 3 heifers/pen). There was a total of 8 pens in this study (4 pens per treatment). Each pen was equipped with a GrowSafe System (GrowSafe Systems Ltd., Alberta, Canada) to determine individual heifer intake. Heifers were fed diets consisting of $100 \%$ alfalfa at $3.40 \%$ BW, on a DM basis, once daily, and allowed ad libitum access to water and Easylix 12-12-12 mineral pressed blocks (Hubbard Feeds, Mankato, MN). Hay was not chopped or altered in any way for feeding. Heifers were fed at $3.40 \mathrm{~g} / \mathrm{kg} \mathrm{BW}$, on a DM basis, because it was found that heifers would consume an unreasonable amount of hay if allowed ad libitum access. The number of bales available for use in this study were limited and it was necessary to limit to intake in order to have enough hay to meet the prerequisite 84-day recommendation for a valid feeding trial. Ort collection was implemented only on the days when the heifers left unwanted feed behind. Orts were collected into small buckets, examined, and weighed. Orts 
were minimal and generally consisted of crushed leaves and dust, with the appearance of stems being negligible.

Heifers were acclimated to their respective treatments 10 days prior to the start of the trial. No data were recorded during this time. Heifers were weighed immediately prior to the start of the trial on day -1 and 0 , and every 27 and 28 days thereafter. Unshrunk weights were taken for two consecutive days, and individual BW were averaged to obtain individual BW by period. Sampling occurred on days $-1,0,27,28,55,56,83$, and 84 . Body weight and DMI were used to determine ADG.

\subsection{Forage Analysis}

Forage nutritive quality was analyzed using core samples taken with a Penn State electric drill mounted hay probe (Nasco Corporation, Modesto, CA). The protocol used for obtaining hay samples using an electric drill mounted hay probe is described by Filley (2005). Samples of both the HX-4114 alfalfa and the WL336HQRR alfalfa were taken during feeding one time each week (every Monday) to ensure an adequate number of samples were collected for analysis. Samples were combined bi-weekly for each treatment, totaling six composited samples per treatment $(n=6)$. Samples were dried at $60^{\circ} \mathrm{C}$ to determine partial dry matter, which was used to calculate the amount of feed each heifer would receive on a DM basis. Samples were then ground in a Wiley mill to pass a 2-mm screen and sent to a commercial lab (Cumberland Valley Analytical Services, Hagerstown, MD) to be analyzed for DM ( $1^{\text {st }}$ step included determining partial DM as described by Goering and Van Soest, 1970; $2^{\text {nd }}$ step included placing samples into a force-air dried oven set at $105^{\circ} \mathrm{C}$ for 3 hours as recommended by Shreve et al., 2006), NDF (Van Soest et al., 1991), acid detergent fiber (ADF; AOAC, 2000), crude protein (CP: AOAC, 2000 and FP528 analyzer, LECO Corporation, St. Joseph, MI), acid detergent lignin (ADL; Goering and Van Soest, 1970), net energy for gain (NEg), relative feed value (RFV), relative forage quality (RFQ), total digestible nutrients (TDN), and neutral detergent fiber digestibility at 48 hours (NDFD48; Goering and Van Soest, 1970).

Separate core samples were taken (same method as above) to determine and analyze percent leaf and leaf-to-stem ratio. The leaves and stems of five core samples from each treatment ( $\mathrm{n}$ $=5$ ) were hand-separated and weighed. Weights of the separated leaves and stems were used for analysis.

\subsection{In situ Dry Matter Disappearance}

Four ruminally cannulated Hereford cows $(\mathrm{BW}=595 \pm 35 \mathrm{~kg})$ were fed grass hay ad libitum and alfalfa hay at $1 \% \mathrm{BW}$ once daily. One Dacron bag $(10 \mathrm{~cm}$ x $20 \mathrm{~cm}$; pore size $=50 \mu \mathrm{m})$ per treatment containing $5 \mathrm{~g}$ of forage $(\mathrm{n}=12,6$ per treatment), one grass hay standard $(n=6)$, and one blank bag $(n=6)$ for each time point were placed into a $41 \times 51 \mathrm{~cm}$ polyester mesh bag to allow for easier removal from the rumen. All 28 Dacron bags were placed into a single mesh bag, which was then placed into the rumen of each cow. The mesh bag was removed after 6, 12, 24, 30, 48, 96, and 240 hours. One dacron bag for each treatment (HX-4114, WL336HQRR, grass standard, and blank) was removed from the mesh bag at each of these 
time points and rinsed in cold water until the water ran clear. Excess water was squeezed gently from each bag. Bags were then dried overnight in a forced-air oven at $60^{\circ} \mathrm{C}$. Residue remaining in each bag was used for NDF analysis (Van Soest et al., 1991). This entire procedure was replicated two days following the removal of bags at $240 \mathrm{~h}$. The procedure was replicated because space in the rumen is limited and it was not possible to replicate samples during the first in situ period. Only one Dacron bag for each treatment, at each time point, would fit in the rumen of each cow during the first in situ period. After replicating the procedure, in situ dry matter disappearance values were calculated and averaged from each in situ period, for each cow, at each time point, by taking the dry weight difference before and after the samples were placed in each cow.

\subsection{Statistical Analysis}

All data in this study were analyzed using SAS (version 9.4; SAS Inst. Inc., Cary, NC). Forage nutrient quality data was analyzed using the PROC GLM procedure of SAS. Individual core samples were treated as the experimental unit and treatment and day were set as fixed effects. Leaf-to-stem data and percent leaf data were analyzed using the PROC GLM procedure of SAS with core sample as the experimental unit. Feeding trial data were analyzed as a completely random design using the PROC MIXED procedure of SAS, with heifer as the experimental unit. Treatment and day were set as fixed effects, with heifer as a random effect. In situ data were analyzed using the PROC MIXED procedure of SAS with Dacron bag as the experimental unit. All means in this study were separated using the LSMEANS procedure and considered significant at $P \leq 0.05$, with a trend considered at $P \leq 0.10$.

\section{Results}

\subsection{Forage Analysis}

Forage nutrient quality parameters are reported in Table 1 . There was a difference between treatments in DM $(P=0.01)$, with HX-4114 alfalfa having $922.3 \mathrm{~g} / \mathrm{kg} \mathrm{DM}$ and WL336HQRR alfalfa having $928.7 \mathrm{~g} / \mathrm{kg}$ DM. There were no significant differences $(P \geq 0.11)$ between treatments for CP, ADF, NDF, ADL, NEg, RFV, RFQ, TDN, or NDFD48. The HX-4114 alfalfa in this study did not meet the expected $150-200 \mathrm{~g} / \mathrm{kg}$ reduction in lignin content and $100-150 \mathrm{~g} / \mathrm{kg}$ increase in NDFD and RFQ. When compared to the WL336HQRR alfalfa treatment in this study, the lignin content for the HX-4114 alfalfa was only reduced by 55 $\mathrm{g} / \mathrm{kg}$ and RFQ and NDFD48 only increased by 30 and $20 \mathrm{~g} / \mathrm{kg}$, respectively. Both varieties were extremely high quality, and it is possible that the high quality of the WL336HQRR control could have masked the increased nutrient quality of the HX-4114 variety.

Leaf count and leaf-to-stem ratios are reported in Table 2. There was a trend for an effect of treatment on leaf count $(P=0.06)$ and a positive effect of treatment on leaf-to-stem ratio $(P=$ $0.04)$, with HX-4114 alfalfa having a higher leaf count and leaf-to-stem ratio than WL336HQRR alfalfa. 


\section{Macrothink}

Journal of Agricultural Studies

ISSN 2166-0379

2018, Vol. 6, No. 2

Table 1. Forage nutrient quality for reduced-lignin alfalfa hay (variety HX-4114) and conventional alfalfa hay (variety WL336HQRR) grown in Montana in 2016.

\begin{tabular}{|c|c|c|c|c|}
\hline \multirow[b]{2}{*}{ Item } & \multicolumn{4}{|l|}{ Treatment } \\
\hline & HX-4114 & WL336HQRR & SEM & $P$-value \\
\hline $\mathrm{DM}(\mathrm{g} / \mathrm{kg})$ & 922.3 & 928.7 & 0.13 & 0.01 \\
\hline $\mathrm{CP}(\mathrm{g} / \mathrm{kg})$ & 205.1 & 207.0 & 0.32 & 0.69 \\
\hline ADF (g/kg) & 241.7 & 256.1 & 0.54 & 0.11 \\
\hline NDF $(g / k g)$ & 306.1 & 311.7 & 0.72 & 0.60 \\
\hline $\operatorname{ADL}(g / k g)$ & 56.9 & 60.2 & 0.19 & 0.25 \\
\hline $\mathrm{NEg}, \mathrm{mcal} / \mathrm{kg}$ & 0.88 & 0.84 & 0.01 & 0.31 \\
\hline RFV & 213.71 & 207.43 & 5.82 & 0.47 \\
\hline RFQ & 218 & 212 & 6.31 & 0.53 \\
\hline TDN (g/kg) & 646.7 & 639.6 & 0.33 & 0.18 \\
\hline NDFD $48^{3}(\mathrm{~g} / \mathrm{kg})$ & 474.4 & 464.9 & 0.72 & 0.39 \\
\hline \multicolumn{5}{|c|}{$\begin{array}{l}\text { DM: dry matter; CP: crude protein; ADF: acid detergent fiber; NDF: neutral detergent } \\
\text { fiber; ADL: acid detergent lignin; NEg: net energy for gain; RFV: relative feed value; RFQ: } \\
\text { relative forage quality; TDN: total digestible nutrients; NDFD48: neutral detergent fiber } \\
\text { digestibility at } 48 \text { hours }\end{array}$} \\
\hline
\end{tabular}

Table 2. Leaf count and leaf-to-stem ratio of reduced-lignin alfalfa hay (variety HX-4114) and conventional alfalfa hay (variety WL336HQRR) grown in Montana in

\section{Treatment}

\begin{tabular}{llll} 
Item & HX-4114 & WL336HQRR & $P$-value \\
\hline Leaf count $(\mathrm{g} / \mathrm{kg})$ & 6.2 & 5.3 & 0.06 \\
Leaf: stem & $1.67^{\mathrm{a}}$ & $1.17^{\mathrm{b}}$ & 0.04 \\
\hline
\end{tabular}

${ }^{\mathrm{ab}}$ Within a row, means without a common superscript differ $(P \leq 0.05)$ 


\subsection{Feeding Trial}

Heifers in this study were fed at 3.4\% BW (DM basis), permitting each heifer nearly unrestricted access to feed. This protocol was implemented to ensure adequate intake by all animals in each pen, to warrant a practical feeding application, and to maximize use of limited resources.

Main effects of alfalfa treatment on BW, ADG, DMI, and G:F during the 84-day study period are presented in Tables 3 and 4 . No treatment by day interactions were observed for any of the animal performance parameters $(P \geq 0.05)$. Animal BW did not differ $(P=0.35)$ between treatments at d 0, 28, 56, or 84. Average daily gain, DMI, and G:F did not differ $(P>0.32)$ between treatments for d 0-28, 29-54, or 55-84.

Table 3. Least squared means and standard errors for body weight across dates and treatments for Angus heifers consuming two varieties of alfalfa hay: a reduced-lignin hay (variety HX-4114) and a conventional hay (variety WL336HQRR).

\begin{tabular}{ccccc}
\hline \multicolumn{5}{c}{ Body Weight $(\mathrm{kg})$} \\
\hline Day & HX-4114 & WL336HQRR & SEM & $P$-value \\
\hline 0 & 270 & 270 & 11.82 & 0.96 \\
28 & 302 & 300 & 11.82 & 0.68 \\
56 & 338 & 334 & 11.82 & 0.48 \\
84 & 367 & 363 & 11.82 & 0.43 \\
Avg & 319 & 317 & 4.18 & 0.93 \\
\hline
\end{tabular}

HX-4114: reduced-lignin alfalfa; WL336HQRR: conventional alfalfa

Table 4. Least squared means and standard errors for average daily gain, dry matter intake, and gain-to-feed ratio across dates and treatments for Angus heifers being fed two varieties of alfalfa hay: a reduced-lignin hay (variety HX-4114) and a conventional hay (variety WL336HQRR).

Trait

\begin{tabular}{ccccc|cccc|cccc}
\hline \multicolumn{3}{c|}{ Average Daily Gain (kg) } & \multicolumn{4}{c|}{ Dry Matter Intake (kg) } & \multicolumn{4}{c}{ Gain-to-Feed Ratio } \\
\hline $\mathrm{Da}$ & $\mathrm{R}$ & $\mathrm{C}$ & $\mathrm{S}$ & $P$-val & $\mathrm{R}$ & $\mathrm{C}$ & $\mathrm{S}$ & $P$-val & $\mathrm{R}$ & $\mathrm{C}$ & $\mathrm{SE}$ & $P$-val \\
\hline $0-2$ & 1. & 1. & 0. & 0.34 & 8.6 & 8.6 & 1. & 0.97 & 0. & 0. & 0.0 & 0.24 \\
$28-$ & 1. & 1. & 0. & 0.54 & 10. & 10. & 1. & 0.57 & 0. & 0. & 0.0 & 0.88 \\
$56-$ & 1. & 1. & 0. & 0.87 & 11. & 11. & 1. & 0.92 & 0. & 0. & 0.0 & 0.73 \\
Av & 1. & 1. & 0. & 0.85 & 10. & 9.9 & 1. & 0.69 & 0. & 0. & 0.0 & 0.71 \\
\hline
\end{tabular}

R: reduced-lignin alfalfa hay, variety HX-4114; C: conventional alfalfa hay, variety WL336HQRR 


\section{Macrothink}

\subsection{In situ Dry Matter Disappearance}

In situ dry matter disappearance for each treatment is reported in Table 5. There were no treatment or treatment by time interactions $(P=0.26$ and 0.77 , respectively) for in situ dry matter disappearance (Fig. 1). These results parallel the forage nutrient quality and feeding trial research results discussed in the previous section.

Table 5. Least squared means and standard errors for in situ dry matter disappearance of reduced-lignin (variety HX-4114) and conventional (variety WL336HQRR) alfalfa hay grown in Montana.

\begin{tabular}{ccccc}
\hline \multicolumn{5}{c}{ Disappearance $(\mathrm{g} / \mathrm{kg})$} \\
Time (hours) & HX-4114 & WL336HQRR & SEM & $P$-value \\
\hline 6 & 295 & 234 & 4.32 & 0.16 \\
12 & 383 & 414 & 4.17 & 0.45 \\
24 & 493 & 461 & 4.17 & 0.44 \\
30 & 534 & 505 & 4.17 & 0.49 \\
48 & 526 & 542 & 4.17 & 0.70 \\
96 & 582 & 556 & 4.17 & 0.53 \\
240 & 649 & 623 & 4.32 & 0.54 \\
\hline
\end{tabular}

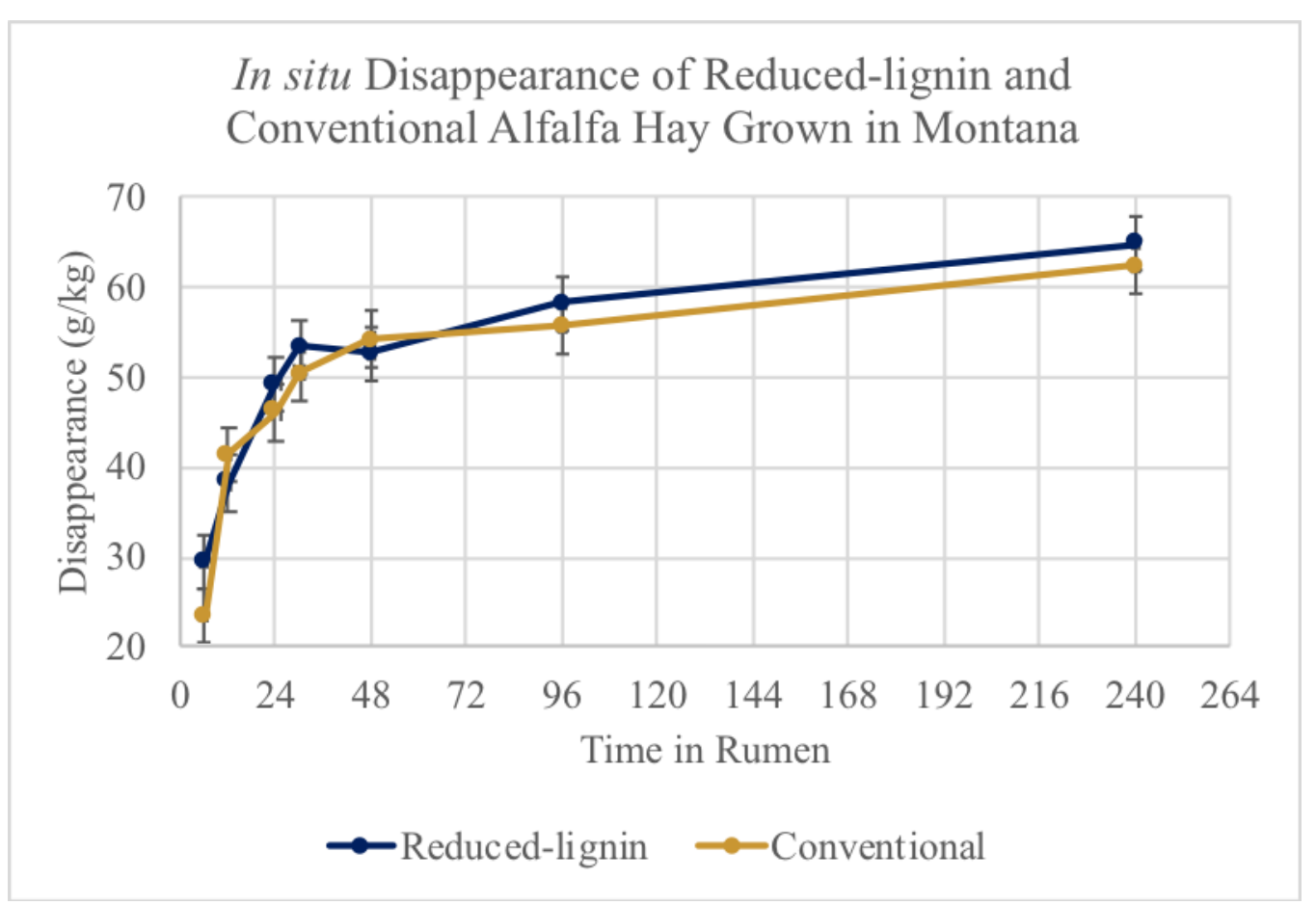

Figure 1. In situ dry matter disappearance at 6, 12, 24, 30, 48, 96, and $240 \mathrm{~h}$ for reduced-lignin (variety HX-4114) and conventional (variety WL336HQRR) alfalfa hay grown in Montana. 


\section{Discussion}

\subsection{Forage Analysis}

Previous preliminary small plot research suggests that the some of the available HarvXtra alfalfa varieties exhibit a reduction in lignin content and improvement in NDFD and RFQ in the environments they were tested in (McCaslin et al., 2014). It was unexpected that forage nutrient value between the HX-4114 and the WL336HQRR alfalfa varieties used in this study did not differ. Based on the results of leaf count and leaf-to-stem ratio, which were higher for the HX-4114 alfalfa variety, we would have expected the HX-4114 alfalfa treatment to have better forage nutrient quality than the WL336HQRR treatment. Leaves are lower in fiber content and more digestible than stems (Albrecht et al., 1987), so it is surprising that the HX-4114 alfalfa did not exhibit lower NDF, ADF, and ADL levels and higher RFQ, TDN, and NDFD48. This result is difficult to explain and follow-up research is needed to address this finding.

One possible explanation for the results of our forage nutrient analysis is the late timing of harvest. Alfalfa harvested later in the year is associated with lower yields and lower quality (Ottman et al., 2014). Alfalfa produced in the fall typically has smaller leaves, lower leaf percentage, and carbohydrates that are being rapidly metabolized due to higher temperatures (Ottman et al., 2014). These factors explain why fiber (NDF and ADF) values are higher and $\mathrm{CP}$ is lower in alfalfa during the fall. Both varieties of alfalfa in this study were rated as "premium quality" and the lignin content was considered low; however, we cannot be certain that late harvest date did not confound the results in this study. It is quite possible that late harvest date is the reason we did not see a reduction in lignin content and an increase in RFQ and NDFD in our reduced-lignin alfalfa.

Another explanation describing the forage nutrient analysis results in this study might be associated with testing the HX-4114 alfalfa variety during the establishment year. Reduced-lignin alfalfa is a relatively new technology and we are unsure as to whether reduced-lignin alfalfa will consistently exhibit reductions in lignin content and increases in RFQ and NDFD during the establishment year as in subsequent years. Comparing the results of our study to the results of other studies (Grev et al., 2017; Guo et al. 2001; Reddy et al. 2005), we find a lack of consistency in the nutrient values of reduced-lignin alfalfa varieties, which may be due to a genotype $\mathrm{x}$ environment effect. More research is warranted to determine differences in forage quality for reduced-lignin alfalfa during the establishment year, and during subsequent years, as well as impact of growing environment on performance.

\subsection{Feeding Trial}

One noticeable observation during this study was the lower ADG and higher DMI during $\mathrm{d}$ 57-84 compared to the ADG and DMI during days 0-28 and days 29-56. Average daily gain and DMI values during this time may have been the result of less efficient use of feed associated with larger animals as they mature or cold stress associated with extreme temperatures. There were extended periods of time during this study (d 57-84) where heifers 
were exposed to extremely low temperatures which are outside of their thermoneutral zone $\left(-5^{\circ}\right.$ and $23.9^{\circ} \mathrm{C}$; Collier et al., 2012). Exposure to cold temperatures outside of their thermoneutral range causes cattle to expend extra energy in order to maintain normal body temperatures. The low and high temperatures for the month of January were $-33^{\circ}$ and $7.22^{\circ} \mathrm{C}$, respectively, with an average of $-12^{\circ} \mathrm{C}$ (Underground, 2016). Houseal and Olson (1995) concluded that animals exposed to lower critical temperatures $\left(-13^{\circ}\right.$ to $-47^{\circ} \mathrm{C}$ depending on size, sex, age plane of nutrition, and previous acclimatization) for prolonged periods of time must increase their metabolic heat production in order to maintain homeostasis. Birkelo et al. (1991) found that cold temperatures increased requirements for both body weight maintenance as well as muscle gain, and when exposed to acute cold stress their feedlot performance was decreased. Therefore, we find it likely that the heifers in our study were cold-stressed during January and February due to the prolonged low temperatures in these months which may have resulted in lower ADG.

Temperature could have been a confounding factor masking any difference in animal performance for heifers being fed the HX-4114 and WL336HQRR alfalfa varieties, although, this is doubtful based on the forage nutrient values of the two varieties. It is possible that we would have seen a difference in overall heifer performance had a different reduced-lignin alfalfa cultivar been used that was better-suited to the environment this study was conducted in.

\section{Conclusion}

Based on the results of this study, additional research is necessary to further explore the quality and value of feeding reduced-lignin alfalfa on growing beef cattle performance. Research exploring the effects of feeding reduced-lignin alfalfa to growing Angus heifers post-seeding year and in a restricted feed setting is necessary to determine the potential impact of reduced-lignin alfalfa on the U.S beef industry.

\section{Acknowledgement}

Funding for this study was provided by Forage Genetics International. Authors wish to express gratitude to the Bozeman Agricultural Research and Teaching Farm and to Amanda Williams and Olivia Fernandez for their assistance with this project.

\section{References}

Albrecht, K. A., Wedin, W.F., Buxton, D.R. (1987). Cell-wall composition and digestibility of alfalfa stems and leaves 1. Crop Science, 27, 735-741.

AOAC. (2000). Official methods of analysis of the AOAC international. $17^{\text {th }} \mathrm{ed}$. Association of Official Agricultural Chemists. Gaithersburg, MD.

Aydin, G., Grant, R., O’Rear, J. (1999). Brown midrib sorghum in diets for lactating dairy cows. Journal of Dairy Science, 82, 2127-2135.

Birkelo, C., Johnson, D., Phetteplace H. (1991). Maintenance requirements of beef cattle as affected by season on different planes of nutrition. Journal of Animal Science, 69, 1214-1222. 
Casler, M.D. and Vogel, K.P. (1999). Accomplishment and impact from breeding for increased forage nutritional value. Crop Science, 39, 12-20.

Cherney, J., Cherney, D., Akin, D., Axtell, J. (1991). Potential of brown-midrib, low-lignin mutants for improving forage quality. Advances in Agronomy, 46, 157-198.

Collier, R.J., Hall, L.W., Rungruang, S., Zimbleman, R.B. (2012). Quantifying heat stress and its impact on metabolizm and performance. Proceedings of the Florida Ruminant Nutrition Symposium, 2012, 74-83.

Filley, S. (2005). Testing Hay. Oregon State University Extension Service, 0502, 1.

Goering, H. K. and Van Soest, P.J. (1970). Forage fiber analyses (apparatus, reagents, prcedures, and some applications). Agriculture Handbook No. 379. ARS-USDA, Washington, DC.

Grev, A.M., Wells, M.S., Samac, D.A., Martinson, K.L., and Sheaffer, C.C. (2017). Forage accumulation and nutritive value of reduced lignin and reference alfalfa cultivars. Agronomy Journal, 109, 2749-2761.

Guo, D., Chen, F., Wheeler, J., Winder, J., Selman, S., Peterson, M., and Dixon, R.A. (2001). Improvement of in-rumen digestibility of alfalfa forage by genetic manipulation of lignin $\mathrm{O}$ methyltransferases. Transgenic Research, 10, 457-464.

Houseal, G., Olson, B. (1995). Cattle use of microclimates on a northern latitude winter range. Can. Journal of Animal Science, 75, 501-508.

Keith, E., Colenbrander, V., Lechtenberg, V., Bauman, L. (1979). Nutritional value of brown midrib corn silage for lactating dairy cows 1, 2. Journal of Dairy Science, 62, 788-792.

McCaslin, M., Reisen, P., Ho, J. (2014). New strategies for forage quality improvement in alfalfa. Proc. California Alfalfa, Forage, and Grain Symposium, 14, 10-12.

Mertens, D. R. (2009). Progress report on reduced-lignin alfalfa: part II, animal digestibility trials. USDA-ARS. Forage Focus. August.

Oba, M. and Allen, M. (1999). Evaluation of the importance of the digestibility of neutral detergent fiber from forage: effects on dry matter intake and milk yield of dairy cows. Journal of Dairy Science, 82, 589-596

Ottman, M., Mostafa, A., Putnam, D. (2014). Summer slump in alfalfa. Progressive Forage. May.

Reddy, M.S.S., Chen, F., Shadle, G., Jackson, L., Aljoe, H., and Dixon, RA. (2005). Targeted down-regulation of cytochrome P450 enzymes for forage quality improvement in alfalfa (Medicago sativa L.). Proceedings of the National Academy of Sciences, 102, 16573-16578.

Rook, J. A., Muller, L., Shank, D. (1977). Intake and digestibility of brown-midrib corn silage by lactating dairy cows 1, 2. Journal of Dairy Science, 60, 1894-1904.

SAS Inc. (2014). Base SAS 9.4 Procedures Guide. SAS Institute. Cary, NC, USA. 


\section{Macrothink}

Journal of Agricultural Studies

ISSN 2166-0379 2018, Vol. 6, No. 2

Shreve, B., Thiex, N., and Wolf, M. (2006). National forage testing association reference method: dry matter by oven drying for 3 hours at 105 C. NFTA Reference Methods. National Forage Testing Association. Omaha, NB.

Underground, W. (2016). Historical weather. Weather Underground.

Van Soest, P. J., Robertson, J., Lewis, B. (1991). Methods for dietary fiber, neutral detergent fiber, and nonstarch polysaccharides in relation to animal nutrition. Journal of Dairy Science, 74, 3583-3597.

\section{Copyright Disclaimer}

Copyright for this article is retained by the author(s), with first publication rights granted to the journal.

This is an open-access article distributed under the terms and conditions of the Creative Commons Attribution license (http://creativecommons.org/licenses/by/4.0/). 